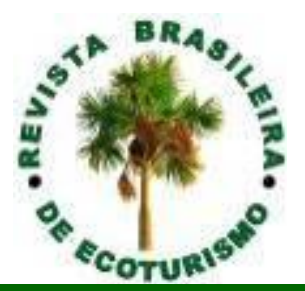

\title{
Trilhas Interpretativas em áreas de Mata Atlântica: um diagnóstico a partir de fotografias hemisféricas
}

\section{Interpretive trails in Atlantic Forest areas: a diagnosis based on hemispherical photographs}

\author{
Marcial Cotes, Daiany Mara Erler, Marcelo Schramm Mielke
}

\begin{abstract}
RESUMO: A presente pesquisa apresenta uma proposta de análise da influência da abertura do dossel florestal no estado de conservação de trilhas interpretativas para a avaliação do impacto de uso em duas Reservas Particulares do Patrimônio Natural (RPPN) no sul da Bahia. O objetivo foi propor a utilização de fotografias hemisféricas capturadas por meio de uma câmera digital montada sobre tripé acoplada a uma lente olho de peixe que permite imagens de 360 graus como ferramenta à formatação e avaliação de impactos de trilhas interpretativas ao ecoturismo. Nas duas trilhas os valores de abertura do dossel florestal foram inferiores a $10 \%$ no interior da mata corroborando com a literatura. A média de abertura do dossel florestal nos pontos interpretativos foi, aproximadamente, $62 \%$ maior na RPPN Ecoparque de Una quando comparada a RPPN Janela da Gindiba. Ao analisar o percurso total de ambas as trilhas a média geral de abertura do dossel florestal foi $51 \%$ maior na RPPN Janela da Gindiba ao confrontar com a RPPN Ecoparque de Una. Os resultados sugerem que a obtenção de dados de abertura do dossel florestal por meio de fotografias hemisféricas pode ser mais uma ferramenta à formatação, avaliação de impactos e auxílio à interpretação e educação ambiental em áreas de Mata Atlântica.
\end{abstract}

PALAVRAS CHAVE: Abertura Dossel; Ecoturismo; Florestas Tropicais; Trilhas Interpretativas.

ABSTRACT: This research aims to analyze the influence of forest canopy openness on the state of conservation of interpretive trails to evaluate the impact on their use in two Private Natural Heritage Reserves (RPPN, acronym in Portuguese) in the southern region of the state of Bahia. It suggests using hemispherical photographs taken with a digital camera on a tripod coupled to a fisheye lens taking 360-degree pictures as a tool to format and evaluate the impacts of interpretive trails on ecotourism. On two trails, the values of forest canopy openness were below $10 \%$ inside the forest, which corroborates the literature. The average value of the forest canopy openness at the interpretive spots was approximately $62 \%$ higher at the RPPN Ecoparque de Una than at the RPPN Janela de Gindiba. Analysis of the total routes of both trails showed that the general average of the forest canopy openness was 51\% higher at the RPPN Janela da Gindiba than at the RPPN Ecoparque de Una. Results suggest that obtaining forest canopy openness data by taking hemispherical photographs may be used as an additional tool to format, evaluate impacts and support environmental interpretation and education in Brazilian rainforest areas.

KEYWORDS: Canopy Openness; Ecotourism; Tropical Forests; Interpretative Trails. 


\section{Introdução}

O ecoturismo tem nas suas diretrizes a relação do ser humano com os ambientes naturais balizadas na interpretação da natureza, na conservação dos locais explorados e na sustentabilidade (BRASIL, 2010). Esta modalidade de turismo é pautada na gestão ambiental dos destinos que serão visitados, haja vista que seus produtos são dependentes das áreas naturais em estado de conservação favoráveis ao seu desenvolvimento (BRASIL, 2010).

As atividades que utilizam o meio ambiente natural para sua realização podem gerar subsídios econômicos ao promover políticas públicas de incremento na região onde são desempenhadas, além de persuadir afirmativamente a conservação de áreas naturais protegidas (HJERPE; 2018; MELO; CRISPIM; LIMA, 2005; MCNEELY; FAITH; ALBERS, 2005).

Tonhasca Jr. (2004; 2005) estima os valores culturais, estéticos, artísticos, científicos, espirituais e de recreação do ecoturismo em áreas de Mata Atlântica. Para o autor a demanda pelas atividades de lazer como caminhadas, ciclismo, canoagem, acampamentos, alpinismo entre outras, neste bioma, caracteriza "a identidade afetiva dos brasileiros com essa floresta" (2004, p. 67). Isto fica evidente quando analisamos o denso povoamento urbano nos domínios da Mata Atlântica brasileira (MAURY, 2002).

O bioma Mata Atlântica abarca um conjunto de formações florestais e ecossistemas associados, incluindo as florestas ombrófilas, restingas, manguezais e campos de altitude. Apresenta diversidade e endemismo elevados sendo considerada um dos hotsposts mundiais (COLOMBO; JOLY, 2010; MYERS et al., 2000).

No sul da Bahia a Mata Atlântica exibe uma grande biodiversidade de flora e fauna em razoável estado de conservação (ARAUJO et al., 1998; MARTINI et al., 2008; THOMAS et al., 2009). No corredor Central da Mata Atlântica, entre o sul da Bahia e o norte do Espírito Santo, ocorre à floresta ombrófila densa ${ }^{1}$ associada à presença de elevados índices pluviométricos, manguezais, restinga, campos de altitude, brejos interiores e outras florestas. Esta floresta, no sul baiano, compreende árvores com dossel elevado que podem atingir $60 \mathrm{~m}$ de altura, densa e com distribuição heterogênea. A cobertura espessa e uniforme do dossel permite um sombreamento na parte inferior da floresta acarretando uma limitação na presença de espécies arbóreas no seu sub-bosque ${ }^{2}$ (BRASIL, 2006; NOGUEIRA JUNIOR et al., 2019).

Ao considerar que caminhar por trilhas onde a ausência de cobertura florestal nos expõe a radiação ultravioleta, podendo causar queimaduras sérias, além do incomodo que a luminosidade excessiva provoca podendo trazer prejuízo a nossa visão, mesmo em áreas de Mata Atlântica, é prudente nos precaver. A literatura indica que as células iniciam um processo irreversível de degradação a partir de $41^{\circ} \mathrm{C}$ e que a "[...] temperatura corporal de $43^{\circ} \mathrm{C}$ é letal para seres humanos; e que quase todas as células são mortas se sua temperatura exceder $50^{\circ} \mathrm{C}$ por alguns minutos" (ASHCROFT, 2001, p. 110). Neste sentido, precauções devem ser levadas em consideração ao realizarmos uma trilha. 
O ser humano possui mecanismos de regulação da temperatura corporal e nem todas as partes do nosso corpo apresentam a mesma tempérie. A temperatura corporal ou basal é definida na literatura como "[...] aquela da profundidade dos tecidos de peito e do abdome" (ASHCROFT, 2001, p. 111). A tempérie é considerada normal quando mantida em torno de $37^{\circ} \mathrm{C}$, podendo alternar pela manhã em cerca de meio grau, no final do período vespertino elevasse mais e antes do anoitecer torna-se um pouco mais baixa (ASHCROFT, 2001).

Devemos levar em consideração que ao percorrer uma trilha estamos submetendo nosso organismo a uma atividade física que poderá ser mais ou menos extenuante, a depender das características deste percurso e do clima. Assim, ao andar por uma trilha mais exaustiva a temperatura no interior dos nossos músculos, que estão mantendo a atividade, pode subir até $41^{\circ} \mathrm{C}$, ainda que a tempérie basal só seja capaz de alternar um ou dois graus (ASHCROFT, 2001).

Ao refletir sobre o exposto, temos que considerar que vivemos em um país tropical e continental, onde as temperaturas aumentam à medida que nos aproximamos da linha do equador. Nesta investigação que ocorreu no nordeste do Brasil, devemos avaliar a propensão do aumento nas séries temporais de temperatura do ar significativas, tanto atuais como nos prognósticos futuros, onde dados estatísticos robustos foram identificados a partir da utilização do teste de Mann-Kendall (SANTOS et al., 2010).

A Empresa Brasileira de Turismo (Embratur) divide a área litorânea do estado da Bahia, localizado ao sul da região nordeste, em cinco polos turísticos nomeados de: Costa das Baleias, do Cacau, dos Coqueiros, do Dendê e do Descobrimento (BAHIA, 2002). A pesquisa hora em tela foi desenvolvida na Costa do Cacau que oferece múltiplas opções de prática de atividades de aventura (COTES; MOREL, 2003).

Logo, alguns estudos já foram implementados na região como, por exemplo: avaliação do nível de dificuldade de trilhas interpretativas (COTES et al., 2007), o desenvolvimento turístico das comunidades locais (NOIA; AVILA; CARTIBANI, 2009), o ecoturismo na visão da comunidade local (TAHARA; SANTOS; CARNICELLI FILHO, 2010), o medo na atividade de aventura (COTES; MOREL, 2011), a análise das ofertas do turismo de aventura (TAHARA; CARNICELLI FILHO, 2012), pesquisa intersetorial ao planejamento do lazer, da cultura e do turismo (SILVA; AVILA; SANTOS; BORGES, 2012); diagnóstico do turismo na ótica dos residentes (SANTOS; AVILA, 2017); investigação sobre as percepções, reflexões e emoções evidenciadas durante o processo educativo de atividade realizada em trilha interpretativa para sensibilizar o visitante (COTES, 2018); e perfil, percepções e sugestões dos visitantes do Parque Estadual do Conduru (AVILA; ROSA, 2018). O que demonstra a vocação da região para o ecoturismo.

Nas florestas tropicais, como é o caso da Mata Atlântica, a diversidade de plantas e animais é determinada, entre outros aspectos, pela quantidade e qualidade de radiação luminosa que chega ao sub-bosque (GASTON, 2000; PURVIS; HECTOR, 2000). As espécies vegetais irão adaptar-se a níveis maiores ou menores de radiação luminosa e produzir biomassa. Já os animais são favorecidos quando se nutrem desta biomassa proveniente, direta ou indiretamente, dos vegetais (GASTON, 2000; PURVIS; HECTOR, 2000). 
Dois fatores significativos na dinâmica de uma floresta são determinados pela disponibilidade de radiação luminosa: a fonte de energia e a variabilidade e desenvolvimento das plantas, concomitantemente a outros aspectos como tempo, espaço, latitude e época do ano (HOGAN; MACHADO, 2002). Estima-se que somente $2 \%$ da radiação solar que incide no alto do dossel de uma floresta tropical alcançam o sub-bosque (HOGAN; MACHADO, 2002).

O dossel florestal é o termo utilizado para designar o conjunto das copas de árvores num determinado ecossistema florestal, abrangendo grande diversidade de interações bioquímicas, físicas e químicas, sendo a porção receptora da maior parte da energia que sustenta esses ecossistemas (GCP, 2004). Pesquisas que utilizam métodos para determinar a disponibilidade de radiação luminosa que atinge o subbosque e a abertura do dossel são empregadas há algum tempo, entretanto, nas últimas décadas estes trabalhos estão sendo utilizados com mais frequência pela facilidade proporcionada pelo uso de câmeras digitais.

Dentre os estudos já desenvolvidos podemos citar o emprego de fotografias hemisféricas para determinar padrões de espaço no interior de florestas tropicais (TRICHON; WALTER; LAUMONIER, 1998), comparações das variações espaciais e temporais e o grau de cobertura do dossel (BIANCHINI; PIMENTA; SANTOS, 2001), nível de regeneração em clareiras (MARTINS; RODRIGUES, 2002), comparação dos resultados de abertura do dossel com a utilização de diferentes tipos de máquinas fotografias e lentes hemisféricas (INOUE et al., 2004), a formação de borda em fragmentos que determina mudanças na abertura do dossel (RAMOS; SANTOS, 2006) e estimativas da abertura do dossel e índice de área foliar (NASCIMENTO; FELFILI; FAGG, 2007).

Além da utilização desta tecnologia digital dentro de florestas tropicais, estudos em trilhas nos mais variados biomas vêm sendo desenvolvidos para a obtenção dos conhecimentos científico, pedagógico e paisagístico (ROCHA et al., 2006; COTES et al., 2007; SILVA; LIMA; PANCHAUD, 2016; COTES et al., 2017; COTES et al., 2017a; COTES, 2018; COTES et al., 2018; PESSOA et al., 2019; BLENGINI et al., 2019; KRUSCHEWSKY; ANDRADE, 2019; SANTOS; SIMÕES; PONCIANO, 2019; NEVES; COSTA, 2019; COSTA et al., 2019; MATINS; DUTRA, 2019; COTES; ALVARENGA; NASCIMENTO, 2020; COTES et al., 2021).

As trilhas são caminhos abertos ou que já existem, os quais apresentam variações na forma, função, distância e nível de dificuldade (COTES et al., 2007). Quanto à forma, uma trilha pode ser classificada em quatro categorias: circular, oito, linear e atalho (LECHNER, 2006). Para Guillaumon et al. (1977) as trilhas são consideradas um impacto do ser humano no meio ambiente natural podendo ser físicos, visuais e sonoros.

Em Unidades de Conservação as trilhas muitas vezes estão localizadas em áreas com vegetação frágil, e, à medida que a sua intensidade de uso aumenta, os impactos são constatados. Por exemplo, ao alterar o fluxo hídrico entre um lado e outro da trilha a sua capacidade de reter água pode inviabilizar os processos de regeneração da flora e da microfauna existente no solo (MAGRO, 1999; LECHNER, 2006). 
Dentre os objetivos de um sistema de trilhas está a significação da natureza, onde trilhas interpretativas são aquelas formatadas após inventário dos pontos potenciais para serem comentados, considerando os seus recursos naturais e culturais, o levantamento e seleção de indicadores de atratividade, os fatores ambientais como diversidade de vegetação, os corpos d'água adjacentes, as áreas históricas ou arqueológicas e a ocorrência de animais silvestres (MAGRO; FREIXÊDAS, 1998). Outro aspecto importante é que podem ser interpretadas por condutores de visitantes ou pelos próprios visitantes por meio de folhetos explicativos e/ou painéis (LECHNER, 2006). Os pontos interpretativos são utilizados com o objetivo de propiciar aos visitantes um momento de percepção do mundo natural e suas sutilezas e exuberância (HESSELBARTH; VACHOWSKI,1999).

As trilhas interpretativas são um dos produtos emergentes do mercado ecoturístico e das manifestações de lazer e aventura na natureza (MALAN). Atualmente, diversos estudos foram publicados visando analisar a sua utilização como ferramenta para a educação ambiental (CORRÊA; FOLETO; COSTA, 2020; ANTUNES; UHMANN, 2020; SOUZA et al., 2020; BLENGINI et al., 2019; GONÇALVES; COTES, 2018; CANTO-SILVA, 2018; SOUZA; CREMER, 2016), a análise das dimensões atitudinais, conceituais e procedimentais dos conhecimentos de condutores de visitantes (COTES; ALVARENGA; NASCIMENTO, 2020), 0 processo de formação e intervenção profissional (DELGADO; COTES, CORRÊA, 2019), a estimativa do gasto energético e sua relação com a percepção dos usuários (KRUSCHEWSKY; ANDRADE, 2019), a sensibilização do usuário (COTES, 2018), o perfil de condutores de visitantes (COTES et al., 2018), as necessidades formativas destes profissionais (COTES et al., 2017), os tipos de aprendizagem dos condutores (COTES et al., 2017a) e o nível de dificuldade (SILVA; LIMA; PANCHAUD, 2016; COTES et al., 2007; ROCHA et al., 2006).

Não obstante, ainda falta na literatura publicações de estudos com o objetivo de analisar a influência do dossel florestal no estado de conservação de trilhas interpretativas em florestas tropicais. Além disto, não identificamos trabalhos que utilizam fotografias hemisféricas como ferramenta à formatação e a avaliação do impacto de uso de trilhas interpretativas, revelando uma lacuna nesta área de pesquisa.

Portanto, o objetivo desse estudo é propor o uso de fotografias hemisféricas como ferramenta para a formatação e avaliação de trilhas interpretativas voltadas ao mercado ecoturístico. Nesta pesquisa, foram utilizadas fotografias hemisféricas para comparar duas trilhas interpretativas em área de Mata Atlântica no sul da Bahia, na região denominada de Costa do Cacau. Assim, este estudo espera contribuir com o ecoturismo e o manejo de trilhas pensando no retorno hedonista ${ }^{3}$ que estas informações poderão gerar ao visitante.

\section{Material e Métodos}

\section{Caracterização da área de estudo}

Os dados da pesquisa foram coletados entre os meses de agosto e outubro em duas trilhas interpretativas em Reservas Particulares do Patrimônio Natural (RPPNs) localizadas em áreas de Mata Atlântica e próximas da cidade de Ilhéus, sul 
da Bahia, Brasil. O clima da região é do tipo tropical úmido e quente com chuvas de verão e outono, sem estação seca e com pluviosidade superior a $1.300 \mathrm{~mm} / \mathrm{ano}$ (FROTA,1972). A cidade de llhéus e o seu entorno possui clima que apresenta temperaturas médias anuais que variam entre $22^{\circ}$ a $25^{\circ} \mathrm{C}$, sendo na faixa litorânea maiores e com menor amplitude térmica. $O$ índice de precipitação apresenta gradiente com total anual superior a $1.000 \mathrm{~mm}$, podendo atingir $2.700 \mathrm{~mm}$ na faixa litorânea (dados CEPLAC/CEPEC/CLIMATOLOGIA). Em função das características climáticas, a vegetação é denominada floresta perenifólia latifoliada higrófila hileana, nomeada de Atlântica (CEPLAC,1975).

A agricultura na microrregião de llhéus e baseada no sistema agroflorestal (SAF) Cabruca, que consiste no raleamento seletivo da vegetação do sub-bosque da Mata Atlântica com o objetivo de deixar as árvores maiores e emergentes para sombrear as plantações de cacau, sistema este que somente ocorre na região sul da Bahia (SAMBUICHI et al. 2012; LOBÃO, 2007). Este SAF denominado de Cabruca impede que grandes áreas florestais sejam desmatadas e permite a formação de corredores ecológicos em áreas de expansão agrícola contribuindo para a manutenção da biodiversidade (SAMBUICHI et al. 2012; LOBÃO, 2007; SCHÄFFER; PROCHNOW, 2002). No entanto, essa atividade agrícola não tem sido economicamente viável nos últimos anos, haja vista a chegada da doença vassourade-bruxa ${ }^{4}$ que causou perdas severas nos rendimentos econômicos da região (FREITAS; PARAíSO, 2001). Associada a isso, houve uma queda no preço do cacau fazendo com que essas áreas fossem substituídas por outras atividades econômicas de maior impacto ambiental como a pecuária extensiva, cafezais e madeireiras (CAMPANILI; PROCHNOW, 2006).

Aliado à história e cultura da denominada por Adonias Filho (1976) "Civilização do Cacau", o turismo surge como opção de desenvolvimento à cidade mais famosa do sul da Bahia descrita e conhecida mundialmente pela literatura do escritor baiano Jorge Amado. Além disso, a cidade de llhéus possui diversos atributos por ser uma região de belezas cênicas elevadas com lindas paisagens naturais marcadas pela Mata Atlântica, praias paradisíacas, cachoeiras e rios (BAHIATURSA, 2000). Ilhéus e seu entorno são reconhecidos pelo potencial turístico de esportes como nado em águas abertas, barco à vela, remo, stand-up, paddle, surfe, prática de vôlei e futebol, turismo cultural em museus, igrejas, teatro e turismo ecológico para aqueles que buscam a natureza (BARROCO, 1998).

\section{Trilha interpretativa da RPPN Ecoparque de Una}

A trilha interpretativa da RPPN Ecoparque de Una (coordenadas geográficas $15^{\circ} 10^{\prime} 16^{\prime \prime S}$ e $39^{\circ} 3^{\prime} 31 " \mathrm{~W}$ ) está localizada a $30 \mathrm{~km}$ ao sul de llhéus, aproximadamente, no município de Una e tem característica linear com $2.100 \mathrm{~m}$ de distância total. Possui como principal diferencial, o trecho com quatro passarelas suspensas em forma de "L" intercaladas por três plataformas (Figura 1 e 2) com aproximadamente $97 \mathrm{~m}$ entre copas de árvores (COTES et al., 2007). A estrutura de passarelas suspensas possibilita ao visitante ter a perspectiva da floresta vista de cima o que pode influenciar no nível de satisfação do visitante. 


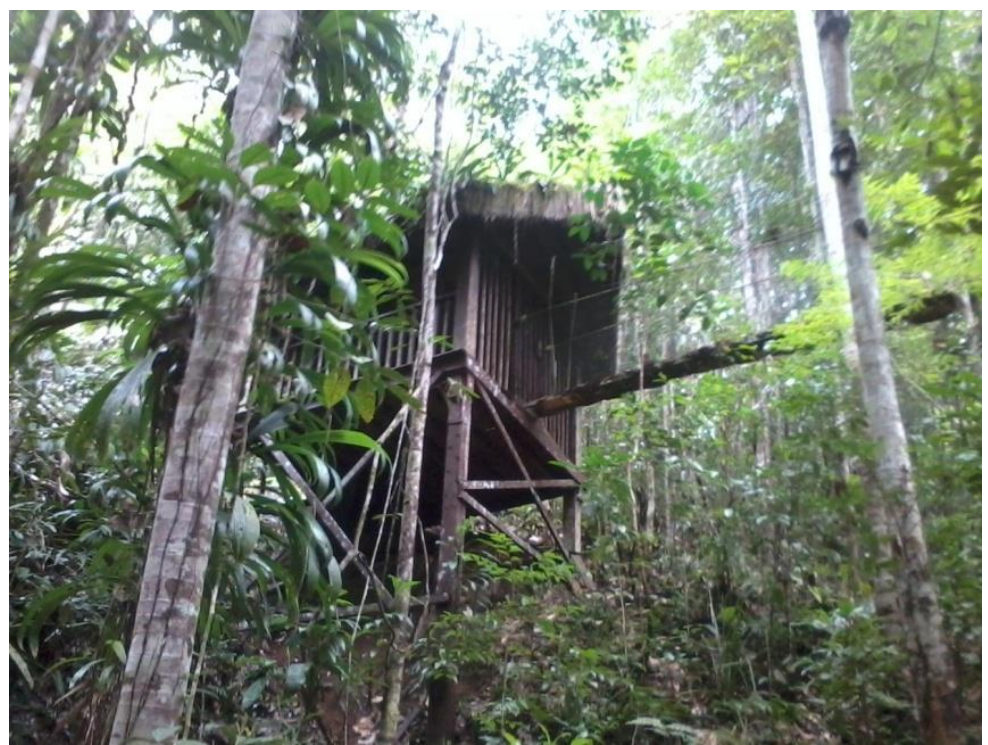

Figura 1: Entrada no trecho de passarelas suspensas da trilha do Ecoparque de Una.

Figure 1: Entrance in the stretch of suspended walkways of the Ecoparque de Una trail.

Fonte: Foto dos autores.

Source: Photo of the authors.

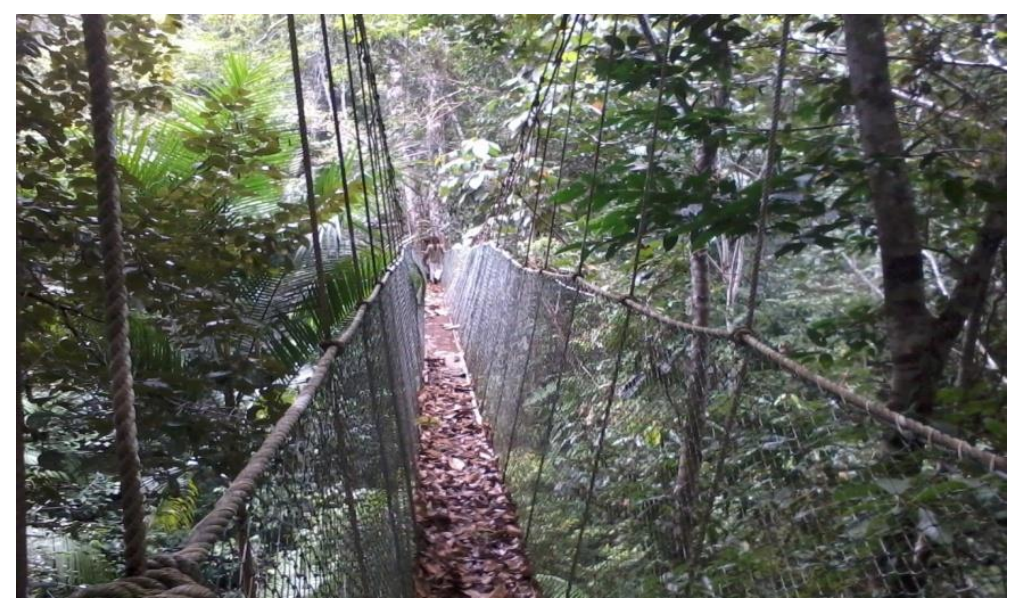

Figura 2: Trecho de passarelas suspensas da trilha do Ecoparque de Una.

Figure 2: Stretch of suspended walkways of the Ecoparque de Una trail.

Fonte: Foto dos autores.

Source: Photo of the authors.

\section{Trilha interpretativa da RPPN Janela da Gindiba}

A trilha interpretativa da RPPN Janela da Gindiba está localizada a uma distância de $60 \mathrm{~km}$ ao norte de llhéus, aproximadamente, na fazenda Bela Vista (coordenadas geográficas $14^{\circ} 12^{\prime} 01^{\prime} \mathrm{W}$ e $39^{\circ} 01^{\prime} 04^{\prime \prime} \mathrm{S}$ ) no distrito de Serra Grande, Uruçuca, Bahia. Conta com $1650 \mathrm{~m}$ de distância, onde os $425 \mathrm{~m}$ iniciais atravessam um SAF até entrar em área de mata primária. Seu grande atrativo é uma gindiba (Sloanea $s p$.) com cerca de $25 \mathrm{~m}$ de altura que curiosamente tem uma janela natural - buraco em torno de $30 \mathrm{~cm}$ de diâmetro - em sua raiz tabular. Quanto ao formato, em seus $425 \mathrm{~m}$ iniciais é linear seguida de trecho circular de mata com aproximadamente $800 \mathrm{~m}$ e retorna ao trecho inicial de SAF. 


\section{Fotografias Hemisféricas}

As fotografias hemisféricas foram capturadas com uma câmera digital Nikon Coolpix 4300 equipada com uma lente olho-de-peixe $\left(180^{\circ}\right)$ no qual foi montada sobre tripé, a aproximadamente $1,5 \mathrm{~m}$ de altura, com a lente apontada ao dossel da floresta e nivelada em relação ao solo com nível do tipo bolha. Além de marca na lente que era direcionada ao norte magnético em todas as imagens. As fotografias foram registradas de 50 em 50 metros em todo percurso de ambas as trilhas e nos seus respectivos pontos interpretativos. As imagens foram analisadas por meio do software livre Gap Light Analyzer (GLA) (FRAZER et al., 1999) para a obtenção dos valores de abertura do dossel em cada ponto fotografado (Figura 3 - A e B).

Foto A / Photo A

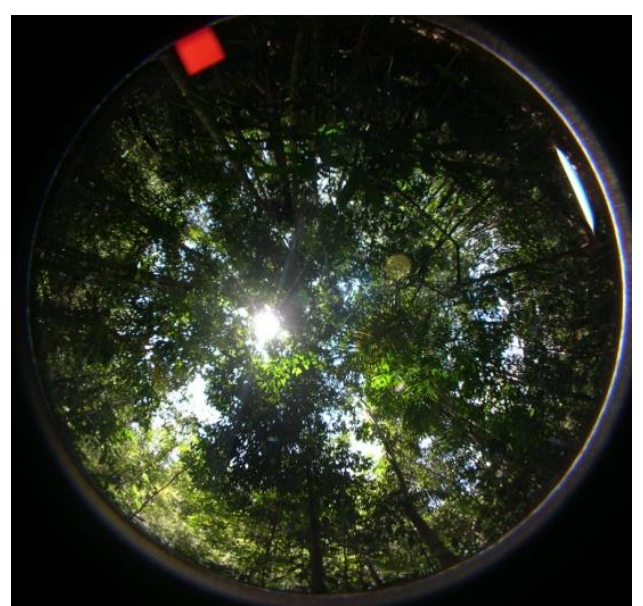

Foto B / Photo B

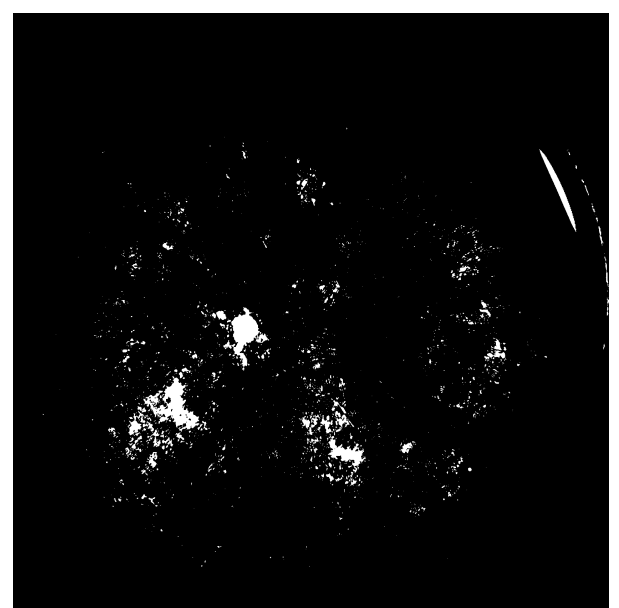

Figura 3: Fotografias hemisféricas coloridas sem tratamento $(A)$ e após o processo de binarização ${ }^{5}$ da imagem (B). Correspondem aos valores de abertura do dossel (AD) do ponto 40 da Trilha do Ecoparque de Una.

Figure 3: Hemispheric color photographs without treatment $(A)$ and after the image binarization process $(B)$. They correspond to the canopy openness values (AD) of point 40 of the Una Ecopark Trail.

\section{Resultados e discussão}

Os dados obtidos nesse estudo indicam que ambas as trilhas, excluindo as áreas de SAF, apresentam valores de abertura do dossel semelhantes aos resultados descritos por Ramos e Santos (2006) e Martins e Rodrigues (2002) em áreas de Mata Atlântica. Onde na maior parte do percurso realizado no interior da floresta os valores de abertura de dossel (AD) foram inferiores a 10\% (Figura $4 \mathrm{~A} \mathrm{e}$ B).

Apesar de estarem localizadas em ambiente de Mata Atlântica, no sul da Bahia, as duas trilhas interpretativas têm características muito distintas, que incluem a distância percorrida, o número e a localização dos pontos interpretativos (Figura 4 A e B). Uma observação interessante refere-se ao fato de que a média de AD nos pontos interpretativos foi aproximadamente $62 \%$ maior na RPPN Ecoparque de Una (Tabela 1) quando comparada com a RPPN Janela da Gindiba (Tabela 2). No entanto, considerando o percurso total que inclui áreas de plantio, a média geral de AD foi $51 \%$ maior na RPPN Janela da Gindiba (Tabela 2) ao confrontar com os 
dados obtidos na RPPN Ecoparque de Una (Tabela 1). Apesar das diferenças nos valores de $A D$ que poderiam dificultar o percurso para a maioria dos visitantes, a distância das trilhas pode compensar o tempo de exposição aos valores mais elevados de AD.

Tabela 1: Caracterização geral da Trilha Interpretativa da RPPN Ecoparque de Una, indicando os pontos inicial e final da trilha, os pontos de caracterização de vegetação, os pontos interpretativos

$(\mathrm{PI})$, as passarelas suspensas e plataformas, a distância percorrida e a abertura do dossel (AD).

Table 1: General characterization of the Interpretative Trail of the RPPN Ecoparque de Una, indicating the start and end points of the trail, the vegetation characterization points, the interpretive points $(\mathrm{Pl})$, the suspended walkway platforms, the distance covered and the canopy openness (AD).

\begin{tabular}{|c|c|c|c|}
\hline \multicolumn{2}{|r|}{ Pontos Interpretativos e locais de registro de abertura do dossel } & \multirow{2}{*}{$\begin{array}{l}\text { Distância (m) } \\
0\end{array}$} & \multirow{2}{*}{$\begin{array}{l}A D(\%) \\
11,3\end{array}$} \\
\hline 1 & 1ํ PI Início da trilha & & \\
\hline 2 & Seringueiras & 50 & 35,5 \\
\hline 3 & Seringueiras & 150 & 45,0 \\
\hline 4 & Floresta em regeneração & 200 & 14,9 \\
\hline 5 & 20 PI Biriba & 204 & 17,6 \\
\hline 6 & Início da floresta nativa & 500 & 4,7 \\
\hline 7 & 3 PI Bromelias & 525 & 5,2 \\
\hline 8 & 4 PI Tronco de árvore em decomposição & 611 & 6,1 \\
\hline 9 & 5 PI Pequi Amarelo & 725 & 4,5 \\
\hline 10 & 6 PI Copaíba & 833 & 4,9 \\
\hline 11 & Início das passarelas no dossel & 850 & 3,2 \\
\hline 12 & 1' Plataforma no dossel & 868 & 6,5 \\
\hline 13 & 2ª Plataforma no dossel & 900 & 17,2 \\
\hline 14 & 3a Plataforma no dossel & 936 & 6,1 \\
\hline 15 & Final das passarelas no dossel & 950 & 5,5 \\
\hline 16 & 7º PI Cachoeira & 1.222 & 5,0 \\
\hline 17 & Floresta nativa & 1.550 & 2,4 \\
\hline 18 & 8 PI Sauveiro & 1.591 & 7,0 \\
\hline 19 & Seringueiras & 1.600 & 4,6 \\
\hline 20 & Final da trilha & 2.100 & 9,3 \\
\hline \multicolumn{2}{|c|}{ Média pontos interpretativos } & & 15,4 \\
\hline \multicolumn{2}{|r|}{ Média passarelas dossel (incluindo plataformas) } & & 7,7 \\
\hline \multicolumn{2}{|c|}{ Média geral } & & 10,8 \\
\hline
\end{tabular}

$\mathrm{Na}$ trilha interpretativa da RPPN Janela da Gindiba, por outro lado, as explicações iniciais são feitas sob a cobertura de um pequeno galpão, onde os visitantes podem fazer os preparativos necessários e se abastecerem de água. Esse fato atenua o percurso de cerca de $400 \mathrm{~m}$ feito quase todo a pleno sol (Figura $4 \mathrm{~B} \mathrm{e}$ Tabela 2).

A partir do primeiro até o quinto ponto interpretativo o trajeto é acontece sob a sombra da floresta, como demonstrado pelos baixos valores de AD (Figura $4 \mathrm{~B}$ e Tabela 2) corroborados pela literatura (RAMOS; SANTOS, 2006; MARTINS; 
RODRIGUES, 2002). Apenas no final da trilha, que corresponde a uma pequena represa ainda no interior da floresta, foi obtido um valor de $A D$ que pode ser reputado como alto. Considerando o aspecto circular dessa trilha, o percurso de ida se torna mais agradável ao visitante do que o percurso de retorno.
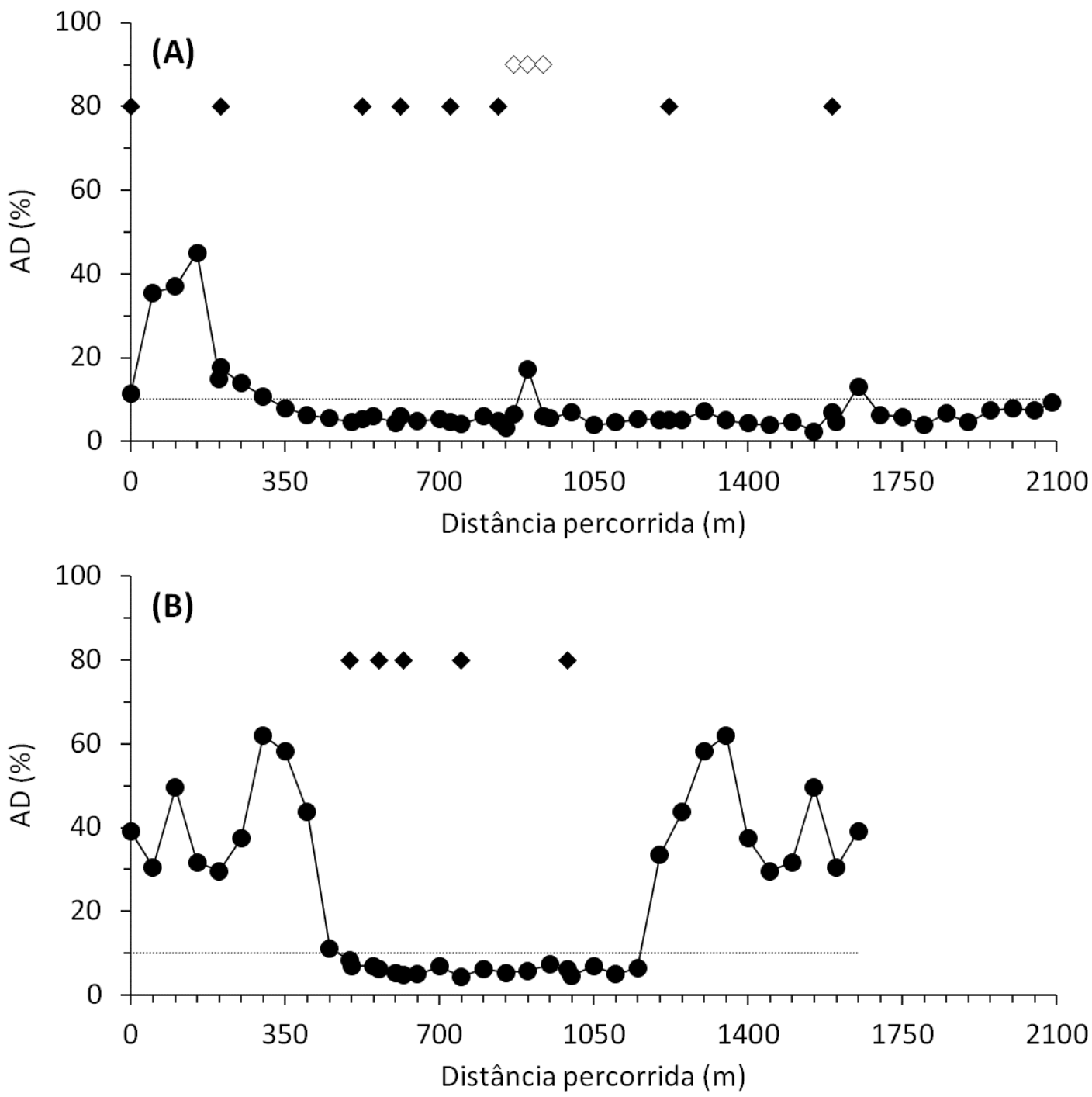

Figura 4. Abertura do dossel (AD) ao longo das trilhas interpretativas da RPPN Ecoparque de Una (A) e Janela da Gindiba (B) em função da distância percorrida. Diamantes em preto correspondem aos pontos interpretativos e diamantes em branco correspondem às plataformas suspensa na trilha da RPPN Ecoparque de Una. A linha pontilhada corresponde ao valor de AD igual a 10\%.

Figure 4. Canopy openness (AD) along the interpretive trails of the RPPN Ecoparque de Una (A) and Janela da Gindiba (B) in function on the distance covered. Black diamonds correspond to the interpretative points and white diamonds correspond to the suspended walkway platforms on the trail of the RPPN Ecoparque de Una. The dotted line corresponds to the AD value equal to $10 \%$. 
As diferenças encontradas nos valores de AD podem ser explicadas pelas características e finalidade de uso das propriedades onde as trilhas estão inseridas. A RPPN Janela da Gindiba tem como finalidade primeira um SAF comercial, além de ser explorada pelo ecoturismo. Em contrapartida a RPPN Ecoparque de Una explora a trilha interpretativa com objetivo ecoturístico, mantendo a plantação de seringueiras (Hevea brasiliensis) somente como mais um atrativo ao visitante, onde o condutor demonstra como é feito a retirada do látex.

Tabela 2: Caracterização geral da Trilha Interpretativa da RPPN Janela da Gindiba, indicando os pontos inicial e final da trilha, os pontos de caracterização de vegetação, os pontos interpretativos

(PI), a distância percorrida e a abertura do dossel (AD).

Table 2: General characterization of the RPPN Interpretative Trail Janela da Gindiba, indicating the start and end points of the trail, the vegetation characterization points, the interpretative points $(\mathrm{PI})$, the distance covered and the canopy openness (AD).

\begin{tabular}{llll}
\hline Pontos Interpretativos e locais de registro de abertura do dossel & \multicolumn{2}{c}{ Distância (m) } & AD (\%) \\
\hline 1 & Início da trilha & 0 & 39,1 \\
2 & Sistema agroflorestal & 400 & 43,8 \\
3 & Início da floresta nativa & 450 & 11,1 \\
4 & 10 PI em área de floresta nativa & 496 & $\mathbf{8 , 3}$ \\
5 & $\mathbf{2}$ P PI Conduru e Angelim Coco & 563 & $\mathbf{6 , 2}$ \\
6 & 3o PI Janela da Gindiba & 618 & $\mathbf{4 , 8}$ \\
7 & $\mathbf{4}$ PI em área de floresta nativa & $\mathbf{7 5 0}$ & $\mathbf{4 , 3}$ \\
8 & $\mathbf{5}$ P Pl árvore c/ câncer (homem elefante) & $\mathbf{9 9 0}$ & $\mathbf{6 , 1}$ \\
9 & Final da represa 15 m antes da saída da floresta nativa & 1.200 & 33,5 \\
10 & Sistema agroflorestal & 1.250 & 43,8 \\
11 & Final da trilha & 1.650 & 39,1 \\
\hline Média pontos interpretativos & & $\mathbf{5 , 9}$ \\
\hline Média geral & & $\mathbf{2 1 , 8}$ \\
\hline
\end{tabular}

Do ponto de vista da educação ambiental, sugerimos a disponibilização de mapas e tabelas da $A D$ em trecho previamente estabelecidos - locais com maior e menor abertura de dossel nos pontos interpretativos existentes na trilha -, permitindo a parada do visitante para observar as diferentes formas de estruturas do dossel florestal, como um procedimento didático-pedagógico de percepção da cobertura florestal e suas nuances (Figura $4 \mathrm{~A}$ e B). É importante ressaltar que trilhas com maior abertura de dossel exigem mais atenção quanto ao uso de equipamentos de proteção individual (EPI), tais como: boné ou chapéu, camisa de proteção solar UV, protetor solar e óculos escuros, comparadas às com menor incidência de luminosidade. Outro aspecto a ser considerado é a necessidade de hidratação durante o percurso (ASHCROFT, 2001).

Logo, o uso de fotografias hemisféricas pode ser mais uma ferramenta para comparar a sensação de bem-estar nos trechos de maior luminosidade quando confrontados com os trechos de menor incidência de luz. Entendemos que ao incluir placas explicativas sobre o dossel florestal e sua biodiversidade associada aos valores de $A D$ em cada ponto interpretativo, poderá gerar um impacto positivo na 
visitação e facilitar a compreensão do visitante quanto à necessidade de se proteger contra os raios do sol (ASHCROFT, 2001), mesmo em áreas de floresta.

Indicamos ainda 0 desenvolvimento da Interpretação Ambiental à conscientização e sensibilização quanto ao meio ambiente (COTES, 2018), avaliar os impactos e os efeitos da visitação e a capacidade de suporte no espaço natural ao fazer um levantamento das principais espécies vegetais e animais presentes nas trilhas. Ademais, propor aos visitantes, sugestões de ações que possam ser desenvolvidas para melhorar a qualidade da visitação.

\section{Considerações Finais}

Os pesquisadores envolvidos no estudo entendem que existem limitações nos resultados obtidos devido ao objeto da pesquisa que foi propor a utilização do recurso de fotos hemisféricas como mais uma ferramenta para contribuir na formatação e avaliação de impactos de trilhas interpretativas voltadas ao ecoturismo, pois não encontramos na literatura estudos que envolvam esses dois recursos: trilhas interpretativas e fotografias hemisféricas.

Os valores de $A D$ nas duas trilhas interpretativas e nos trechos que correspondem à floresta nativa estão de acordo com os relatos da literatura para outras áreas de Mata Atlântica. No entanto, ao comparar as trilhas entre si, as diferenças encontradas nos valores de AD para os sistemas agroflorestais parecem estar relacionadas com o tempo de implantação dos mesmos e o manejo das áreas.

A partir dos dados da pesquisa entende-se ser indispensável à atenção redobrada dos condutores de visitantes ao aspecto hidratação, antes durante e depois da trilha evitando desta forma problemas decorrentes da exposição ao sol durante a atividade física de caminhar em um ambiente natural. Além da utilização de Equipamentos de Proteção Individual (EPIs) para prevenção contra os raios solares.

Os resultados sugerem que a obtenção de dados de $A D$ por meio de fotografias hemisféricas pode ser uma ferramenta útil e eficaz para a formatação de trilhas, analise do impacto de uso e educação ambiental em áreas de Mata Atlântica voltadas ao ecoturismo.

\section{Referências}

ALVES, S. A. M. Epidemiologia da vassoura-de-bruxa (Crinipellis perniciosa (Stahel) Singer) em cacaueiros enxertados em Uruçuca, BA. Dissertação de Mestrado apresentada à escola Superior de Agricultura Luiz de Queiroz, 2002.

ANTUNES, E.; UHMANN, R. I. M. Concepções de Educação Ambiental no ensino de Ecologia em atenção às estratégias de ensino: uma revisão bibliográfica. Rev. Eletrônica Mestr. Educ. Ambient. Rio Grande, v. 37, n. 1, p. 109-126, 2020.

ARAUJO, M.; KEITH, A.; ROCHA, R.; MESQUITA, C. A. B. A mata atlântica do sul da Bahia. Série Cadernos da Reserva da Biosfera da Mata Atlântica. São Paulo: Consehlo Nacional da Reserva da Biosfera da Mata Atlântica; 1998. 
ASHCROFT, F. M. A vida no limite: a ciência da sobrevivência. Trad. Maria Luiza X. de A. Borges. Rio de Janeiro: Zahar, 2001.

AVILA, M. A.; ROSA, C.D. Parque Estadual do Conduru: perfil, percepções e sugestões dos visitantes. Revista Brasileira de Ecoturismo, v.11, n.3, p.66-72, 2018.

BAHIA. Roteiros Ecoturísticos da Bahia Costa do Cacau (2a ed.). Secretaria de Cultura e Turismo da Bahia, Superintendência de Desenvolvimento do Turismo. Salvador: Bahia, 2002.

BAHIATURSA. A estratégia turística da Bahia: 1991 - 2005 / Bahiatursa. Salvador: Omar G. Coleção Selo Turismo, 1.Turismo - Bahia. I. Título. II Série, 2000.

BARROCO, H. E. Retrospectiva e prospectiva para a micro-região llhéus/ltabuna. Especiarias. Ilhéus: Editus, Ano 1, n. 1, 1998.

BERRY, P. E. Diversidad y endemismo em los bosques neotropicales de bajura. In: Manuel R. Guariguata; Gustavo H. Kattan. Ecología y conservación de bosques neotropicales. Catargo: Ediciones LUR, 2002.

BIANCHINI, E.; PIMENTA, J.A.; SANTOS, F.A.M. Spatial and temporal variation in the canopy cover in a tropical semi-deciduous forest. Brazilian Archives of Biology and Technology, v. 44, p. 269-276, 2001.

BLENGINI, I.A.D.; LIMA, L.B.; SILVA, I.S.M.; RODRIGUES, C. Trilha interpretativa como proposta de Educação Ambiental: um estudo na RPPN do Caju (SE). Revista Brasileira de Ecoturismo, São Paulo, v.12, n.1, 2019.

BRASIL. O corredor central da Mata Atlântica: uma nova escala de conservação da biodiversidade. Ministério do Meio Ambiente, Conservação Internacional e Fundação SOS Mata Atlântica, Brasília, 2006.

BRASIL. Ministério do Turismo. Ecoturismo: orientações básicas. Ministério do Turismo, Secretaria Nacional de Políticas de Turismo, Departamento de Estruturação, Articulação e Ordenamento Turístico, Coordenação Geral de Segmentação. 2 ed., Brasília: Ministério do Turismo, 2010.

CAMPANILI, M; PROCHNOW, M. Mata Atlântica: uma rede pela floresta. Brasília: RMA, 2006.

CALVO-VARGAS, I. M. Importancia de los recursos interpretativos autoguiados, como promotores de la conservación de los recursos naturales. Tecnología en Marcha. Edición especial. Movilidad Estudiantil, v. 6, p. 35 - 46, 2019.

COLOMBO, A. F.; JOLY, C. A. Brazilian Atlantic Forest lato sensu: the most ancient Brazilian forest, and a biodiversity hotspot, is highly threatened by climate change. Braz. J. Biol., v.70, n.3, p.697-708, 2010.

COMISSÃO EXECUTIVA DO PLANO DE RECUPERAÇÃO DA LAVOURA CACAUEIRA. Recursos Florestais. Diagnóstico Sócio-econômico da Região Cacaueira, no 7. Ilhéus, CEPLAC/IICA, 1975.

CORRÊA, L. R.; FOLETO, E. M.; COSTA, F. S. Interpretação ambiental através dos programas de uso público das Reservas Particulares do Patrimônio Natural Federais. Rev. Eletrônica Mestr. Educ. Ambient. Rio Grande, v. 37, n. 1, p. 166187, jan/abr. 2020. 
COSTA, P. G.; PIMENTEL, D. S.; SIMON, A. V. S.; CORREIA, A. R. Trilhas Interpretativas para o Uso Público em Parques: Desafios para a Educação Ambiental. Revista Brasileira de Ecoturismo, v.12. n.5, p.818 - 839, 2019.

COTES, M.; MIELKE, M. S.; CAZORLA, I. M.; MOREL, M. Avaliação do nível de dificuldade da trilha interpretativa do Ecoparque de Una (Ba): aspectos físicos, biológicos e parâmetros de esforço físico dos visitantes. Revista Brasileira de Ciências do Esporte, Campinas, v. 28, n. 3, p. 191-207, 2007.

COTES, M.; SALLES, W. N.; TOZETTO, A. V. B.; NASCIMENTO, J. V. Aprendizagem formal, não formal e informal: como condutores de dois Parques Nacionais estabelecem seu tirocínio. Movimento, v.23, n.4, p.1381-1394, 2017.

COTES, M.; SALLES, W. N.; SCHIAVETTI, A.; NASCIMENTO, J. V. Necessidades formativas de condutores de visitantes em Parques Nacionais. Revista Brasileira de Ecoturismo, v.10, n.4, p.892 - 917, 2017a.

COTES, M.; SALLES, W. N.; BRASIL, V. Z.; IHA, T.; SCHIAVETTI, A.; NASCIMENTO, J. V. Perfil sociodemográfico, acadêmico e profissional de condutores de trilhas de longa duração em Parques Nacionais Brasileiros. Revista Brasileira de Ciência e Movimento, v. 26, n. 1, 167-177, 2018.

COTES, M. Interpretative trail: a tool to awareness. Motricidade, v. 14 , p. $78-84$, 2018.

COTES, M.; ALVARENGA, A. M.; NASCIMENTO, J. V. Attitudinal, conceptual, and procedural dimensions of the knowledge of trail guides in national parks. Motriz Journal of Physical Education, Rio Claro, v. 26, Issuel, 2020.

COTES, M.; ERLER, D. M.; SCHIAVETTI, A.; NASCIMENTO, J. V. O legado de Niède Guidon no semiárido brasileiro: a percepção de condutores de visitantes do Parque Nacional Serra da Capivara. Antípoda - Revista de Antropología y Arqueología, n. 42, p. 179-204, 2021.

DELGADO, M.; COTES, M.; CORRÊA, E. A. Atividades de aventura: entre a formação e a intervenção do profissional de educação física. In: Cotes, M.; Nunes, F. S.; Mussi, R. F. F. (Org.), Lazer e meio ambiente: pesquisa, extensão e práticas pedagógicas. Goiânia: Kelps, p. 33 -51, 2019.

ELLENBERG, H.; MUELLER-DOMBOIS, D. Tentative key to a physiognomic classifica tion of plant formations of the earth, based on a discussion draft of the UNESCO working group on vegetation classification and mapping - Sine loc, 1967.

FRAZER, G.W., CANHAM, C.D.; LERTZMAN, K.P. Imaging software extract canopy structure and gap light transmission indices from true-colour fisheye photographs, users manual and program documentation. Gap Light Analyzer (GLA). Version 2.0. New York, Simon Fraser University, Burnaby, British Columbia, and The Institute of Ecosystem Studies, Millbrook, 1999.

FREITAS, A. F. G.; PARAíSO, M. H. B. Caminhos ao encontro do mundo: a capitania, os frutos de ouro e a princesa do sul - Ilhéus, 1534 - 1940. Ilhéus: Editus, 2001. 
FROTA, P. C. E. Notas sobre o clima da Região Cacaueira Baiana. Cacau. Atualidades (Brasil) 9(2): 17-24, 1972.

GASTON, K. J. Global patterns in biodiversity. Nature, v. 405, p. 220-227, 2000.

GCP. Earth, living Planet! Florestas onde a biodiversidade encontra o clima. CD Rom GCP, INPA e LBA. Brasília, 2004.

GONÇALVES, P. C.; CANTO-SILVA, C. R. Elaboração de roteiro para uma trilha interpretativa no Parque Natural Morro do Osso, Porto Alegre (RS). Revista Brasileiro de Educação Ambiental, São Paulo, v. 13, n. 3, p. 122-142, 2018.

GUILLAUMON, J. R.; POLL, E.; SINGY, J. M. Análise das trilhas de interpretação. Bol. Técn. 25. São Paulo, Instituto Florestal, 1977.

HESSELBARTH, W; VACHOWSKI, B. Planejamento, implantação e manejo de trilha. Tradução de Margarida G. Rauen. Org. Fundação O Boticário de Proteção a Natureza, 1999.

HJERPE, E. E. Outdoor Recreation as a Sustainable Export Industry: A Case Study of the Boundary Waters Wilderness. Ecological Economics, v.46, 60-68, 2018.

HOGAN, K. P.; MACHADO J. L. La luz solar: consecuencias biológicas y medición. In: Manuel R. Guariguata; Gustavo H. Kattan. Ecología y conservación de bosques neotropicales. Catargo: Ediciones LUR, 2002.

INOUE, A.; YAMAMOTO, K.; MIZOUE, N.; KAWAHARA, Y. Effects of image quality, size and camera type on forest light environment estimates using digital hemispherical photography. Agricultural and Forest Meteorology, v.126, p. 89-97, 2004.

KRUSCHEWSKY, A.; ANDRADE, C. S. Estimativa do gasto energético e sua relação com a percepção dos usuários durante caminhada em trilha de unidade de conservação no sul da Bahia. In: Cotes, M.; Nunes, F. S.; Mussi, R. F. F. (Org.), Lazer e meio ambiente: pesquisa, extensão e práticas pedagógicas. Goiânia: Kelps, p. $235-248,2019$.

LECHNER, L. Planejamento, implantação e manejo de trilhas em Unidades de Conservação. Trad. Jan Gerd Shöenfelder. Cadernos de Conservação, Fundação o Boticário de Proteção à Natureza, ano 03, no 03, Curitiba, 2006.

LOBÃO, D. É. Agroecossistema cacaueiro da bahia: cacau cabruca e fragmentos florestais na conservação de espécies arbóreas. Tese (Doutorado). Universidade Estadual Paulista. Jaboticabal-SP, 2007.

MAGRO, T. C. Impactos do uso público em uma trilha no planalto do Parque Nacional do Itatiaia. Tese (Doutorado) -- Escola de Engenharia de São Carlos Universidade de São Paulo, São Carlos, 1999.

MAGRO, T. C.; FREIXÊDAS, V. M. Trilhas: como facilitar a Seleção de Pontos Interpretativos. Circular Técnica IPEF, n. 186, 1998.

MARTINI, A. M. Z.; FIASCHI, P.; AMORIM, A. M.; PAIXÃO, J. L. A hot-point within a hot-spot: a high diversity site in Brazil's Atlantic Forest. Biodiversity and Conservation, v. 16, n. 11, p. 3111-3128, 2007. 
MARTINS, S. V.; RODRIGUES, R.R. Gap-phase regeneration in a semideciduous mesophytic forest, south-eastern Brazil. Plant Ecology, v. 00, p. 1-12, 2002.

MAURY, C. M. (org.) Avaliação e identificação de áreas e ações prioritárias para conservação, utilização sustentável e repartição dos benefícios da biodiversidade nos bimas brasileiros. Brasília: MMA/SBF, 2002.

MYERS, R.; MITTERMEIER, R. A.; MITTERMEIER, C. G.; FONSECA, G. A. B.; KENT, J. Biodiversity hotspots for conservation priorities. Nature, v. 403, p. 853-858, 2002. doi: $10.1038 / 35002501$

MCNEELY, J. A.; FAITH, D. P.; ALBERS, H. J. "Biodiversity". En Ecosystems and human well-being: Policy responses, v. 3. Millennium Ecosystem Assessment Series, (Org.) Kanchan Chopra, Rik Leemans, Pushpam Kumar y Henk Simons. Washington D.C.: Island Press, n. 3, p. 119-172, 2005.

MELO, R.S; CRISPIM, M.C.; LIMA, E.R.V. O turismo em ambientes recifais: em busca da transição para a sustentabilidade. Caderno Virtual de Turismo, v.5, n.4, p.34-42, 2005.

NASCIMENTO, A. R. T.; FELFILI, J. M. ; FAGG, C. W. Canopy openness and lai estimates in two seasonally deciduous forests on limestone outcrops in central Brazil using hemispherical photographs. Revista Árvore, v. 31, n. 1, p. 167-176, 2007.

NEVES, C. R. F.; COSTA, V. C. Avaliação Preliminar de Risco (APR) em atividades ecoturísticas na trilha do Pico da Tijuca, Parque Nacional da Tijuca (RJ). Revista Brasileira de Ecoturismo, São Paulo, v.12, n. 5, p. 685 - 701, 2019.

NOGUEIRA JUNIOR, L.R.; DOMPIERI, M. H. G.; CRUZ, M. A. S. GeoTAB: Identificação dos biomas e da vegetação na região de atuação da Embrapa Tabuleiros Costeiros. Scientia Plena, v. 15, n. 11. 2019.

PESSOA, F. A.; BRITO, A. F. S.; PACHECO, F. F.; PEIXOTO, M. N. O.; MANSUR, K. L. Patrimônio geomorfológico e interpretação ambiental em trilhas de montanha (Parque Nacional da Serra dos Órgãos, Rio de Janeiro, Brasil). Revista Ibero-AfroAmericana de Geografia Física e Ambiente \& Iberian-African-American Journal of Physical Geography and Environment, v. 1, n. 2, 121-138, 2019.

PURVIS, A.; HECTOR, A. Getting the measure of biodiversity. Nature, 405: p.212 219, 2000.

RAMOS, F. N.; SANTOS, F. A. M. Microclimate of Atlantic Forest Fragments: Regional and Local Scale Heterogeneity. Brazilian Archives of Biology and Technology, v.49, n. 6, p. 935-944, 2006.

SAMBUICHI, R. H. R.; VIDAL, D. B.; PIASENTINI, F. B.; JARDIM, J. G.; VIANA, T.; MENEZES, A. A.; MELLO, D. L. N.; AHNERT, D.; BALIDAR, V. C. Cabruca agroforest in southern Bahia, Brazil: tree component, management practices and tree species conservation. Biodivers Conserv., 21, p. 1055-1077, 2012.

SANTOS, L.B.M.; SIMÕES, B.F.T.; PONCIANO, L.C.M.O. Ecoturismo e Conservação na Área de Proteção Ambiental do Morro do Cachambi, Rio de Janeiro: pela tessitura das vozes geopoéticas em trilhas. Revista Brasileira de Ecoturismo, São Paulo, v.12, n.5, p. 653 - 684, 2019. 
SANTOS, D. N.; SILVA, V. P. R.; SOUZA, F. A. S.; SILVA, R. A. Estudo de alguns cenários climáticos para o Nordeste do Brasil. R. Bras. Agríc. Ambiental, v. 14, n. 5, p. 492-500, 2010.

SCHÄFFER, B., W.; PROCHNOW M. Mata Atlântica e você: como preservar, recuperar e se beneficiar da mais ameaçada floresta brasileira. Brasília: APREMAVI, 2002.

SOUZA, B. R.; FRIZZO, T. C. E.; ROCHA, D. A. S.; DELACROIX, R.. Escola, Universidade e Unidade de Conservação: a Educação Ambiental como conexão, um estudo de caso em Itapuã - RS. Rev. Eletrônica Mestr. Educ. Ambient. Rio Grande. v. 37, n. 1. Seção especial: XI EDEA - Encontro e Diálogos com a Educação Ambiental. p. 336-346. jan/abr. 2020.

SOUZA, D. M.; CREMER, M. J. A trilha ambiental interpretativa em uma unidade de conservação como ferramenta de sensibilização de escolares: uma abordagem quantitativa na Rede Municipal de ensino de Joinville, Santa Catarina. Pesquisa em Educação Ambiental, v. 11, n. 1, p. 94-109, 2016.

THOMAS, W. W. et al. Composição florística e estrutura do componente arbóreo de uma área transicional de Floresta Atlântica no sul da Bahia, Brasil. Rev. bras. Bot., v. 32, n.1, p.65-78, mar. 2009.

TRICHON, V.; WALTER, J.N.; LAUMONIER, Y. Identifying spatial patterns in the tropical rain forest structure using hemispherical photographs. Plant Ecology, v. 137, p. 227-244, 1998.

TONHASCA Jr., Athayde. Os serviços ecológicos da Mata Atlântica. Ciência Hoje, v. 35, n. 205, p. $64-67,2004$.

TONHASCA Jr., Athayde. Ecologia e historia natural da Mata Atlântica. Rio de Janeiro: Ed. Interciência, 2005.

\section{Notas:}

${ }^{1}$ Em 1967, Ellemberg e Mueller-Dombois alteram o termo, até então utilizado, de floresta pluvial para Floresta ombrófila densa. Este tipo de floresta é descrita com vegetação de mata perenifólia, ou seja, que se apresenta sempre verde e com o dossel florestal podendo atingir mais de $50 \mathrm{~m}$ em algumas regiões, com ocorrência de árvores emergentes. Árvores emergentes são aquelas mais altas que as demais, cuja copa fica acima do dossel da floresta. A floresta ombrófila densa além de possuir uma vegetação arbustiva é composta por samambaias, palmeiras, trepadeiras e epífitas (bromélias e orquídeas), bem como os cactos e as samambaias.

${ }^{2} \mathrm{Na}$ área de conhecimento de botânica sub-bosque é o termo empregado para mencionar um conjunto de vegetação de baixa altura que se desenvolve sob o dossel florestal. Sua vegetação constitui-se da combinação de mudas e plantas jovens de árvores do dossel, juntamente com arbustos do sub-bosque e ervas.

${ }^{3}$ Neste texto, compreenda a palavra "hedonismo" como a doutrina caracterizada pela busca do prazer como propósito mais significante da vida moral, segundo a qual o prazer dos sentidos seria o fundamento de todos os outros prazeres espirituais. Acarretando desta forma uma propaganda positiva à trilha percorrida. 
${ }^{4}$ Trata-se da doença fúngica denominada de Moniliophtera perniciosa considerada a mais relevante no cultivo do cacau nos países onde têm ocorrência. Ao depositar basidiósporos que são esporos desenvolvidos por meio da meiose a partir dos basídios e que dão origem às hifas de fungos (basidiomicetos, basidiogonídio, basidiogônio, basidiospório) sobre as gemas vegetais ou florais e nos frutos jovens em crescimento, a infecção se manifesta caracterizada por necróticos que aparecem quando a planta dá início ao processo de brotação.

${ }^{5}$ Processo pelo qual é feito a conversão de uma imagem colorida para uma representação binária de dois tons, a saber, preto e branco. Este processo é relevante para possibilitar a identificação pelo programa do que é área foliar, galhos e troncos na cor preta e da luminosidade na tonalidade branca.

\section{Agradecimentos}

Aos proprietários das RPPNs Janela da Gindiba e Ecoparque de Una.

Marcelo S Mielke agradece ao CNPq pela bolsa de produtividade em pesquisa.

Marcial Cotes: Universidade Estadual de Santa Cruz (UESC), Ilhéus, Bahia, Brasil.

E-mail: mcotes@uesc.com

Link ORCID: https://orcid.org/0000-0002-6345-3715

Link para o currículo Lattes: http://lattes.cnpq.br/3234372265353297

Daiany Mara Erler: Mestrado de Sistemas Aquáticos Tropicais da Universidade Estadual de Santa Cruz (UESC), Ilhéus, Bahia, Brasil.

E-mail: daiany.erler@gmail.com

Link ORCID: https://orcid.org/0000-0002-5006-9167

Link para o currículo Lattes: http://lattes.cnpq.br/1622166154015093

Marcelo Schramm Mielke: Universidade Estadual de Santa Cruz (UESC), Ilhéus, Bahia, Brasil.

E-mail:msmielke@uesc.br

Link ORCID: https://orcid.org/0000-0001-6930-2902

Link para o currículo Lattes: http://lattes.cnpq.br/9035736743125906

Data de submissão: 26 de maio de 2020

Data de recebimento de correções: 04 de novembro de 2020

Data do aceite: 04 de novembro de 2020

Avaliado anonimamente 